\title{
Risk factors for mortality in infants with congenital diaphragmatic hernia: a single center experience
}

\author{
Jennifer Bettina Brandt (iD · Tobias Werther · Erika Groth · Erik Küng · Johann Golej · Angelika Berger
}

Received: 29 June 2020 / Accepted: 27 February 2021 / Published online: 30 March 2021

(C) The Author(s) 2021

\begin{abstract}
Summary
Background Despite current progress in research of congenital diaphragmatic hernia, its management remains challenging, requiring an interdisciplinary team for optimal treatment.

Objective Aim of the present study was to evaluate potential risk factors for mortality of infants with congenital diaphragmatic hernia.

Methods A single-center chart review of all patients treated with congenital diaphragmatic hernia over a period of 16 years, at the Medical University of Vienna, was performed. A comparison of medical parameters between survivors and non-survivors, as well as to published literature was conducted.

Results During the observational period 66 patients were diagnosed with congenital diaphragmatic hernia. Overall survival was $84.6 \%$. Left-sided hernia occurred in 51 patients $(78.5 \%)$ with a mortality of $7.8 \%$. In comparison, right-sided hernia occurred less frequently $(n=12)$ but showed a higher mortality $(33.3 \%$, $p=0.000$ ). Critically instable patients were provided with venoarterial extracorporeal membrane oxygenation (ECMO, 32.3\%, $n=21$ ). Survival rate among these patients was $66.7 \%$. Right-sided hernia, treatment with inhaled nitric oxide (iNO) over 15 days and the
\end{abstract}

J. B. Brandt, MD $(\bowtie) \cdot$ T. Werther, MD $\cdot$ E. Küng, MD ·

J. Golej, MD · A. Berger, MD, MBA

Comprehensive Centre for Paediatrics, Division

of Neonatology, Paediatric Intensive Care \&

Neuropaediatrics, Department of Paediatric and Adolescent

Medicine, Medical University of Vienna, Waehringer

Guertel 18-20, 1090 Vienna, Austria

jennifer.brandt@meduniwien.ac.at

\section{E. Groth}

Department of General Medicine, Glasgow Royal Infirmary, Glasgow, UK use of ECMO over 10 days were significant risk factors for mortality.

Conclusion The survival rate in this cohort is comparable to the current literature. Parameters such as the side of the diaphragmatic defect, duration of ECMO and inhaled nitric oxide were assessed as mortality risk factors. This analysis of patients with congenital diaphragmatic hernia enhances understanding of risk factors for mortality, helping to improve management and enabling further evaluation in prospective clinical trials.

Keywords CDH · Pulmonary hypertension - ECMO . Inhaled nitric oxide $\cdot$ Survival parameters

$\begin{array}{ll}\text { Abbreviations } \\ \text { BW } & \text { Birth weight } \\ \text { CDH } & \text { Congenital diaphragmatic hernia } \\ \text { GA } & \text { Gestational age } \\ \text { ICU } & \text { Intensive care unit } \\ \text { iNO } & \text { Inhaled nitric oxide } \\ \text { L-CDH } & \text { Left-sided CDH } \\ \text { PH } & \text { Pulmonary hypertension } \\ \text { R-CDH } & \text { Right-sided CDH } \\ \text { VA ECMO } & \text { Venoarterial extracorporeal membrane } \\ & \text { oxygenation }\end{array}$

\section{Introduction}

Congenital diaphragmatic hernia $(\mathrm{CDH})$ occurs in approximately 1 in 2500-5000 live births [1, 2]. Research in animal models has enhanced knowledge of its pathogenesis, involving developmental abnormalities of the pleuroperitoneal fold [3]. Neonates with $\mathrm{CDH}$ often present with additional malformations and chromosomal aberrations [4]. Management of these patients is a demanding challenge and requires a multidisciplinary team [5]. Mortality rates of $\mathrm{CDH}$ range 
from $52 \%$ to $82 \%$, varying among pediatric centers and depending on various factors and comorbidities $[6,7,8]$. Different risk factors including side of defect, position of liver, necessity of extracorporeal membrane oxygenation (ECMO), pulmonary hypertension $(\mathrm{PH})$ and additional congenital anomalies contribute to the high mortality $[2,9,10]$.

The aim of this study was to perform a retrospective chart review of $\mathrm{CDH}$ in a single tertiary pediatric center, to analyze risk factors for mortality and to compare the results with the current literature.

\section{Patients and methods}

This study was conducted as a single center analysis at the Medical University of Vienna. We performed a retrospective chart review of all infants diagnosed with $\mathrm{CDH}$ and treated at our neonatal or pediatric intensive care unit (ICU) between 2000 and 2015, to analyze risk factors for mortality and to compare results with current literature. All participants were born either in this center or another Austrian hospital and were transferred to our department before $\mathrm{CDH}$ repair was performed. Primary outcome was survival until discharge from the ICU. We created a retrospective registry including the following demographic and medical parameters: gender, gestational age (GA), birth weight (BW), side of defect, position of liver, length of stay in ICU, presence of additional congenital comorbidities, $\mathrm{PH}$ including treatment with inhaled nitric oxide (iNO), timing of surgical intervention, operational technique and surgical complications, as well as necessity and length of ECMO treatment (Medtronic Biomedicus 560 centrifugal pump, Dublin, Ireland).

Descriptive statistics were presented as mean and standard deviation (SD) or range for continuous variables and as absolute and relative frequencies for categorical variables. A data comparison was performed between survivors and non-survivors (until discharge from or death in the ICU). For determination of statistical significance in categorical variables a $\chi^{2}$-test was used, while continuous variables calculations were conducted by using the two-tailed unpaired $t$-test. Statistical significance was considered to be achieved with a $p$-value $<0.05$. The $p$-values were not adjusted for multiple testing and have to be interpreted as explorative only. For variables with a $p$ value $<0.05$ in the univariate analysis, relative risk was calculated, using a $2 \times 2$ table with Haldane correction as appropriate, unconditional maximum likelihood estimation for confidence intervals and a mid-P exact test for significance. Univariate analysis and data visualization were performed using the $\mathrm{R}$ statistic environment with the ggplot2 package $[11,12]$. Data collection was performed in Excel(C) (Microsoft Cooperation, Albuquerque, New Mexico, United States, Version 15.19.1).
Table 1 Characteristics of survivors and non-survivors

\begin{tabular}{|c|c|c|c|}
\hline Characteristics & $\begin{array}{l}\text { Survivors } \\
(n=55)\end{array}$ & $\begin{array}{l}\text { Non-survivors } \\
(n=10)\end{array}$ & $p$-value \\
\hline Female, $n$ & $24(43.6)$ & $5(50)$ & 0.71 \\
\hline $\begin{array}{l}\text { Gestational age at birth, } \\
\text { weeks (SD) }\end{array}$ & $37.6(1.9)$ & $37.2(2.3)$ & 0.48 \\
\hline Birth weight, g (SD) & 2949 (570) & 2406 (541) & 0.56 \\
\hline Vaginal delivery, $n^{\mathrm{a}}$ & $14(25.5)$ & $0(0)$ & 0.09 \\
\hline Out-born, $n$ & $20(36.4)$ & $4(40)$ & 0.83 \\
\hline $\begin{array}{l}\text { Length of stay in ICU, days } \\
\text { (SD) }\end{array}$ & $16.9(23.6)$ & $17.7(14.2)$ & 0.31 \\
\hline \multicolumn{4}{|l|}{ Anomalies } \\
\hline $\mathrm{L}-\mathrm{CDH}, n$ & $47(85.5)$ & $4(40)$ & $<0.001$ \\
\hline Intrathoracic liver, $n^{\text {b }}$ & $28(50.9)$ & $8(80)$ & 0.04 \\
\hline Comorbidities, $n$ & $16(29.1)$ & $3(30)$ & 1.00 \\
\hline $\begin{array}{l}\text { Chromosomal aberrations, } \\
n\end{array}$ & $2(3.6)$ & $0(0)$ & 0.83 \\
\hline Cardiac defects, $n$ & $9(16.4)$ & $2(20)$ & 0.67 \\
\hline Other comorbidities, $n$ & $5(9.1)$ & $1(10)$ & 1.00 \\
\hline \multicolumn{4}{|l|}{ PH and ventilation } \\
\hline Ventilation, days (SD) & $17.4(22.4)$ & 17.7 (14.2) & 0.19 \\
\hline Pulmonary hypertension, $n$ & $37(67.3)$ & $10(100)$ & 0.03 \\
\hline iNO, $n$ & $37(67.3)$ & $10(100)$ & 0.03 \\
\hline $\begin{array}{l}\text { Duration of iNO treatment, } \\
\text { days (SD) }\end{array}$ & $4.5(6.8)$ & $14.7(14.3)$ & 0.02 \\
\hline \multicolumn{4}{|l|}{ ECMO } \\
\hline VA-ECM0, $n$ & $14(25.5)$ & 7 (70) & 0.01 \\
\hline ECM0 treatment, days (SD) & $2.4(4.4)$ & $9.3(11.1)$ & 0.01 \\
\hline \multicolumn{4}{|l|}{ Surgery } \\
\hline Surgical intervention, $n^{\mathrm{C}}$ & $55(100)$ & $7(70)$ & 0.00 \\
\hline Timing of surgery, days (SD) & $9.1(26.6)$ & $10.1(9)$ & 0.05 \\
\hline Patch, $n$ & $18(32.7)$ & $5(50)$ & 0.05 \\
\hline Surgical complications, $n$ & $8(14.5)$ & $2(20)$ & 0.31 \\
\hline Need of reoperation, $n$ & $5(9.1)$ & $2(20)$ & 0.18 \\
\hline \multicolumn{4}{|c|}{$\begin{array}{l}\text { Data are presented as numbers (\%) and mean (SD) unless otherwise indi- } \\
\text { cated. } P \text {-values were calculated using the } \chi^{2} \text {-testor the two-tailed unpaired } \\
\text { t-test } \\
n \text { number, } S D \text { standard deviation, ICU intensive care unit, } L \text {-CDH left sided } \\
\text { congenital diaphragmatic hernia, } P H \text { pulmonary hypertension, } i N O \text { inhalative } \\
\text { nitric oxide, } V A-E C M O \text { venoarterial extracorporeal membrane oxygenation } \\
\text { a In } 5 \text { patients, mode of delivery could not be determined due to lack of } \\
\text { documentation } \\
\text { b For } 2 \text { patients no information about the position of liver was available } \\
{ }^{c} \text { In } 3 \text { patients no operation was performed. Two patients died due to treat- } \\
\text { ment refractory cardiorespiratory failure (one of them on ECMO) and one } \\
\text { patient died on ECMO after severe cerebral hemorrhage, before any surgical } \\
\text { intervention was performed }\end{array}$} \\
\hline
\end{tabular}

\section{Results}

Between 2000 and 2015 a total of 66 patients with $\mathrm{CDH}$ were treated in our center. One patient born at 29 weeks GA with $900 \mathrm{~g} \mathrm{BW}$, who died on the first day of life due to refractory arterial hypotension was excluded from analyses. Overall survival in our cohort was $84.6 \%$. Comparison of demographic and medical data between survivors $(n=55)$ and non-survivors $(n=10)$ is presented in Table 1 . One survivor was treated in our ICU for 133 days. This patient was 
Table 2 Characteristics of patients with left-sided versus right-sided congenital diaphragmatic hernia

\begin{tabular}{|c|c|c|c|}
\hline & L-CDH $(n=51)$ & $\mathrm{R}-\mathrm{CDH}(n=12)$ & $p$-value \\
\hline Survivors, $n$ & $47(92.2)$ & $8(66.7)$ & 0.02 \\
\hline Intrathoracic liver, $n^{\text {a }}$ & $22(43.1)$ & $12(100)$ & 0.002 \\
\hline Intra-abdominal liver, $n^{\mathrm{a}}$ & $27(52.9)$ & $0(0)$ & 0.002 \\
\hline Comorbidities, $n$ & $13(25.5)$ & $5(41.7)$ & 0.30 \\
\hline Cardiac defect, $n$ & $7(13.7)$ & $4(33.3)$ & 0.20 \\
\hline Pulmonary hypertension, $n$ & $35(68.6)$ & $10(83.3)$ & 0.31 \\
\hline iNO, $n$ & $35(68.6)$ & $10(83.3)$ & 0.31 \\
\hline Days of ventilation, mean (SD) ${ }^{b}$ & $15.5(15.6)$ & $27.3(35.6)$ & 0.02 \\
\hline $\mathrm{ECMO}, n^{\mathrm{c}}$ & $15(29.4)$ & $5(41.7)$ & 0.50 \\
\hline Patch repair, $n^{\mathrm{d}}$ & $16(31.4)$ & 7 (58.3) & 0.09 \\
\hline Stitch repair, $n^{d}$ & $34(66.7)$ & $5(41.7)$ & 0.09 \\
\hline \multicolumn{4}{|c|}{$\begin{array}{l}\text { Data are presented as numbers (percentage) and mean (SD) unless other- } \\
\text { wise indicated. } P \text {-values were calculated using the } \chi^{2} \text {-testor the two-tailed } \\
\text { unpaired t-test } \\
n \text { number, } S D \text { standard deviation, } L-C D H \text { left sided congenital diaphragmatic } \\
\text { hernia, } R \text {-CDH right sided congenital diaphragmatic hernia, ECMO extracor- } \\
\text { poreal membrane oxygenation } \\
\text { a In } 2 \text { patients the position of liver could not be determined; both of them had } \\
\text { L-CDH } \\
\text { b In } 4 \text { patients duration of ventilation was missing } \\
{ }^{c} \text { One patient on ECMO had bilateral CDH } \\
\text { d In } 3 \text { patients no intervention could be performed, } 2 \text { of them had bilateral } \\
C D H\end{array}$} \\
\hline
\end{tabular}

transferred to a German CDH center, while still on the ventilator, at parental request.

There was no significant difference between survivors and non-survivors with respect to gender, GA, BW, mode of delivery or place of birth (Table 1). Survival of in-born patients was not higher than of outborn patients ( $n=35,85.4 \%$ vs. $n=20,83.3 \%, p=0.83$ ). The majority of out-born patients, however, underwent surgical repair by stitch $(87.5 \%$ vs. $47.4 \%$ in the in-born cohort, $p=0.001$ ).

Table 2 gives detailed information about patients with left-sided CDH (L-CDH) and right-sided CDH (R$\mathrm{CDH})$. Of all patients $51(78.5 \%)$ were diagnosed with L-CDH and 12 patients (18.5\%) with R-CDH. Mortality in patients with R-CDH was higher compared to patients with $\mathrm{L}-\mathrm{CDH}$ (33.3\% versus $7.8 \%, p=0.02)$. Two patients (3\%) had defects on both sides; both did not survive (one had a complete aplasia of the diaphragm and died due to bleeding on ECMO and the other patient could not be hemodynamically stabilized despite ECMO treatment).

Intrathoracic position of the liver was found in $50.9 \%$ of survivors as opposed to $80 \%$ of non-survivors $(p=0.04)$. Two patient charts did not contain any information about the position of the liver; both had L-CDH. All patients with R-CDH $(n=12)$ and bilateral hernia $(n=2)$ had intrathoracic parts of the liver, as opposed to 22 patients $(43.1 \%)$ with $\mathrm{L}-\mathrm{CDH}$ $(p=0.01$, Table 2). Out of 36 patients $8(22.2 \%)$ with intrathoracic position of the liver died as opposed to only 1 of $27(3.7 \%)$ patients with an entirely intraabdominal position of the liver $(p=0.04)$.
Of the patients 19 (29.2\%) had documented comorbidities, 8 patients had various anomalies, including chromosomal anomalies $(n=2)$, esophageal atresia $(n=1)$, dysmorphic syndrome $(n=1)$, fetofetal transfusion syndrome $(n=1)$, bilateral hydronephrosis with hydroureter $(n=1)$, a congenital cervical tumor $(n=1)$, and a congenital cystic adenomatoid malformation $(n=1)$. The other 11 patients $(57.9 \%)$ had cardiac malformations: atrial septal defect $(n=8)$, stenosis of the pulmonary artery $(n=1)$, pulmonary atresia $(n=1)$ and aortic isthmus stenosis $(n=1)$. A cardiac defect was found in 4 out of 12 patients with R-CDH $(33.3 \%$, $50 \%$ mortality) and 7 out of 51 patients with L-CDH (13.7\%, 0\% mortality, Table 2).

Pulmonary hypertension was diagnosed in 47 patients $(72.3 \%)$. Infants suffering from $\mathrm{PH}$ showed a longer period of mechanical ventilation (21.5 vs. 6.3 mean days, $p=0.02$ ). All 18 patients without PH survived, whereas mortality was $21.3 \%$ in patients with $\mathrm{PH}(n=10, p=0.03)$ and 20 patients on ECMO (95.2\%) had PH. All patients diagnosed with PH received iNO. In 29 patients iNO treatment was continued after surgical repair. Mortality among these patients was $24.1 \%(n=7)$. Mean length of iNO treatment was 6.3 days (SD 9.3 days, longest duration 42 days), with a longer duration in non-survivors (mean 14.7 days, SD 14.3 days) compared to survivors (mean 4.5 days, SD 6.8 days, $p=0.02$ ). Administration of iNO for more than 10 days was associated with a fourfold increase of mortality (Fig. 1).

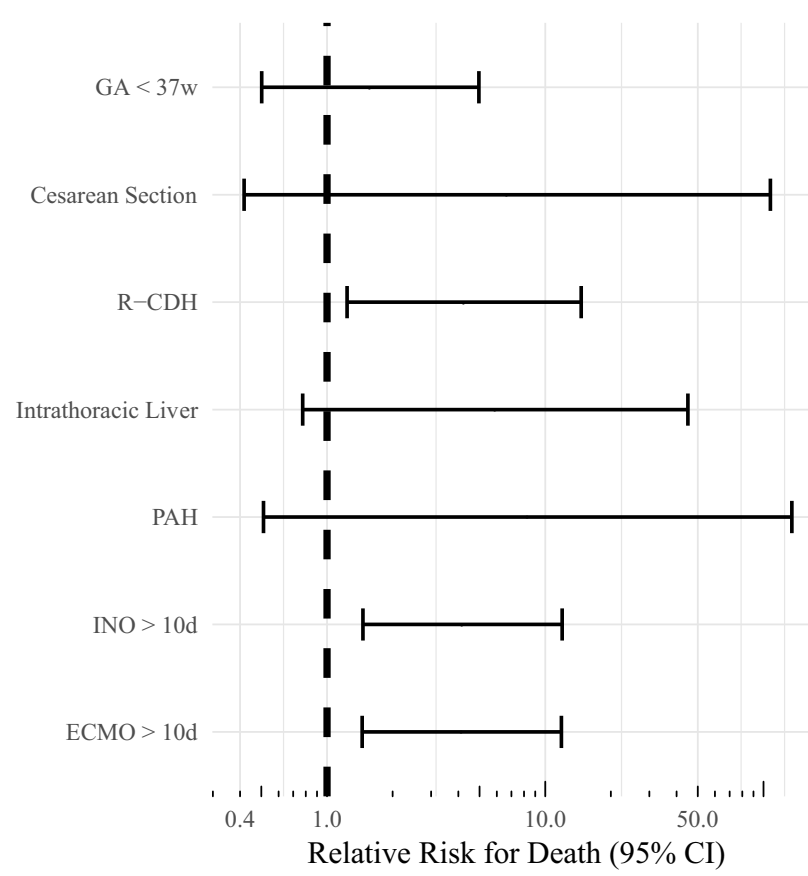

Fig. 1 Relative risk for death in children with congenital diaphragmatic hernia. $G A<37 w$ gestational age below 37 weeks; $R-C D H$ right-sided congenital diaphragmatic hernia, $P A H$ pulmonary hypertension; INO $>10 d$ inhalative nitric oxide over 10 days; ECMO $>10 d$ extracorporeal membrane oxygenation over 10 days, $\mathrm{Cl}$ confidence interval 
Table 3 Characteristics of patients on ECMO versus no ECMO

\begin{tabular}{|c|c|c|c|}
\hline Characteristics & $\begin{array}{l}\text { ECMO } \\
(n=21)\end{array}$ & $\begin{array}{l}\text { No ECMO } \\
(n=44)\end{array}$ & $p$-value \\
\hline Mortality, $n$ & $7(33.3)$ & $3(6.8)$ & 0.01 \\
\hline Gestational age at birth, weeks (SD) & $37.3(2.0)$ & $37.6(2.0)$ & 0.13 \\
\hline Birth weight, g, weight (SD) & $2802.5(510)$ & $2896(634.6)$ & 0.56 \\
\hline Length of stay in ICU, days (SD) & $31.8(32)$ & $9.9(10.4)$ & 0.05 \\
\hline Intrathoracic liver, $n^{\text {a }}$ & $15(71.4)$ & $21(47.7)$ & 0.05 \\
\hline $\mathrm{R}-\mathrm{CDH}, n$ & $5(23.8)$ & $7(15.9)$ & 0.62 \\
\hline Comorbidities, $n$ & $6(28.6)$ & $13(29.5)$ & 1.00 \\
\hline Cardiac defect, $n$ & $4(19)$ & $7(15.9)$ & 0.74 \\
\hline Duration of ventilation, days (SD) & $29.7(31.3)$ & $11.1(8.1)$ & 0.02 \\
\hline Pulmonary hypertension, $n$ & $20(95.2)$ & $27(61.4)$ & 0.004 \\
\hline Duration of iN0 treatment, days (SD) & $11.2(10.5)$ & $3.7(7.5)$ & 0.11 \\
\hline Timing of surgery, days of life (SD) ${ }^{b}$ & $9.2(6.2)$ & $9.3(30.1)$ & 0.001 \\
\hline Patch repair, $n^{b}$ & $11(52.4)$ & $12(27.3)$ & 0.02 \\
\hline Surgical complications, $n^{\text {b }}$ & $5(23.8)$ & $5(11.4)$ & 0.26 \\
\hline \multicolumn{4}{|c|}{$\begin{array}{l}\text { Data are reported as numbers (percentage) and mean }[S D] \text { unless other- } \\
\text { wise indicated. } P \text {-values were calculated using the } \chi^{2} \text {-testor the two-tailed } \\
\text { unpaired t-test } \\
n \text { number, } S D \text { standard deviation, } g \text { grams, } I C U \text { intensive care unit, } \\
L-C D H \text { left sided congenital diaphragmatic hernia, } R \text {-CDH right sided con- } \\
\text { genital diaphragmatic hernia, } P H \text { pulmonary hypertension, } i N O \text { inhalative } \\
\text { nitric oxide, ECMO extracorporeal membrane oxygenation } \\
\text { a In } 2 \text { patients the position of liver was unknown } \\
\text { b Two patients on ECMO had no surgical intervention }\end{array}$} \\
\hline
\end{tabular}

Of all patients 21 (32.3\%) received VA ECMO with an overall mortality of $33.3 \%(n=7$, Table 3$)$ as opposed to $6.8 \%(n=3)$ of patients without ECMO ( $p=0.01)$. Of these patients 2 could not be hemodynamically stabilized and died on ECMO prior to any surgical intervention, ECMO was initiated after a mean of 2.2 days of life $(\mathrm{SD}=3.2$ days), 8 patients were on ECMO only prior to surgery and could successfully be decannulated either before or immediately after the intervention (mean $=9$ days, $\mathrm{SD}=2.3,0 \%$ mortality), 9 patients were still in need of ECMO after surgery (mean $=4$ days, $\mathrm{SD}=2.5,55.6 \%$ mortality) and 2 patients needed ECMO only after surgery (for 9 and 14 days, respectively). Mean length of ECMO treatment overall was 10.8 days (2-36 days, SD 6.6 days). The longest duration of ECMO treatment among survivors was 14 days. Patients receiving ECMO for more than 10 days $(n=10)$ had a mortality of $40 \%$, compared to $27.3 \%$ in patients receiving ECMO for less than 10 days $(n=11, p=0.29)$. The relative risk for death was four times higher in patients on ECMO for more than 10 days (Fig. 1).

Of all patients 62 (95.4\%) underwent surgery, 3 patients $(4.8 \%)$ died before any surgical intervention was performed, 2 of them died on ECMO. Two different methods (patch for larger sized defects or stitch for smaller sized defects) were conducted to repair the diaphragm. Stitch repair was the most common method ( $n=39,62.9 \%)$. Patch repair was performed in 23 patients (37.1\%). Patients with patch-closed hernia showed a trend to increased mortality in comparison to stitch-closed $\mathrm{CDH}$ (patch mortality $21.7 \%$ vs. stitch mortality $5.1 \%, p=0.05$ ). Out of 19 patients on ECMO $11(57.9 \%)$ had a patch repair of the diaphragmatic defect. In contrast, $72.1 \%$ of patients repaired by stitch were not on ECMO $(n=31, p=0.03)$.

\section{Discussion}

In this single-center 16-year experience of 65 patients with congenital diaphragmatic hernia, we report an overall survival of $84.6 \%$. These results are within the upper range of the current literature [7, 8, 13-20]. Right-sided $\mathrm{CDH}$, treatment with iNO $>15$ days and the use of ECMO $>10$ days were significant risk factors for mortality in our cohort. We did not find a significant effect of GA and BW on survival in accordance with Hoffman et al. who showed that BW was not a predictor for mortality in patients on ECMO [21], and Colvin et al. who found no effect of GA on mortality either [6]. Delaplain et al. reported a higher risk of mortality for patients with lower BW [22]. Also, Kadir et al. indicated that risk of mortality declined by $7 \%$ for every $100 \mathrm{~g}$ increase in BW [8]. Survival of in-born patients was not higher than of out-born patients in our cohort. A possible explanation for this finding could be that out-born infants with severe $\mathrm{CDH}$ might have died before transfer, which could not be considered in our analyses due to lack of documentation. In fact, the majority of out-born and transferred patients underwent surgical repair by stitch indicating a less severe and smaller defect of the diaphragm. Our data support the observation that L-CDH occurs more often than R-CDH [3-5] and that overall mortality in infants with R-CDH is higher than in infants with L-CDH [4, 22]. Difficulty of prenatal diagnosis [10], necessity of patch repair $[23,24]$ as well as reoperation are possible reasons for higher mortality among patients with R-CDH [23]. In contrast to data reported by Duess et al. [9] our findings showed no higher demand for ECMO among patients with R-CDH. Intrathoracic localization of the liver has repeatedly been reported to be associated with increased mortality, as also found in our cohort, probably due to distinctive pulmonary hypoplasia [2, 14, 17]. Similarly, our data showed a trend towards increased mortality in patients with patch repair in comparison to stitch repair, as also described in other reports $[9,18,24]$.

Presence of additional comorbidities is known to limit survival [25]. Published trials showed that patients with additional cardiac anomalies have lower chances of survival $[23,26]$. In accordance with published data $[5,26]$, cardiac anomalies were the most frequently documented additional defects in our cohort, although we found no effect on mortality as opposed to Graziano et al. [27]. This discrepancy could be explained by the difference in sample size (65 patients in our cohort as opposed to more than 2600 patients in the study of Graziano et al.) and the exclu- 
sion of atrial septal defects in the study of Graziano et al. due to the lack of hemodynamic significance, which were, however, the most common defects in our cohort. Our data support the observation that survival with extracorporeal support as rescue therapy in severe $\mathrm{CDH}$ is lower compared to patients without requirement of ECMO treatment [6]; however, it has been shown that application of ECMO increases survival of patients who are unresponsive to conventional treatment [21, 23]. Morini et al. demonstrated that mortality rates declined from $83.5 \%$ to $38.3 \%$ when ECMO treatment was applied in patients unresponsive to conventional treatment [28]. In our cohort, $66.7 \%$ of $\mathrm{CDH}$ infants receiving ECMO survived. This percentage is in the upper range of reports in the literature, ranging from $50-75 \%[3,9,15,19,23,30]$. In accordance to published data [29], we observed decreased survival in infants with prolonged need of ECMO treatment. Our data showed a fourfold increase in relative risk of death in patients with ECMO treatment exceeding 10 days, which supports the findings presented by McHoney et al. [5] Pulmonary hypertension has been described as a major risk factor for mortality in patients with $\mathrm{CDH}[1,3]$. Our analysis also showed increased mortality in patients with a diagnosis of $\mathrm{PH}$ as well as longer periods of ventilation, treatment with iNO and necessity of ECMO.

Limitations of this study are its retrospective design and the long time period covered, resulting in incomplete availability of data and individual parameters. On the other hand, given the long time period considered, we were able to report a sufficiently high number of patients to draw conclusions from a singlecenter experience.

In conclusion, our data on basic characteristics, management and outcome of patients with $\mathrm{CDH}$ over a 16-year period in a single tertiary referral center, contribute to the comprehension of predictors for mortality of patients with this rare condition and might help to improve future management of patients with $\mathrm{CDH}$ as well as the design of prospective studies.

Acknowledgements We acknowledge DI Jutta Gamper, BSc. from the Centre for Medical Statistics, Informatics and Intelligent Systems (CeMSIIS), Medical University of Vienna for statistical support in this study.

Funding The authors have no financial relationships relevant to this article to disclose. This research did not receive any specific grant from funding agencies in the public, commercial or non-profit sectors.

Funding Open access funding provided by Medical University of Vienna.

\section{Declarations}

Conflict of interest J.B. Brandt, T. Werther,E. Groth, E. Küng, J. Golej, and A. Berger declare that they have no competing interests.
Ethical standards All procedures performed in studies involving human participants or on human tissue were in accordance with the ethical standards of the institutional and/or national research committee (Medical University of Vienna (EK No 2060/2016)) and with the 1975 Helsinki declaration and its later amendments or comparable ethical standards. Informed consent was obtained from all individual participants included in the study.

Open Access This article is licensed under a Creative Commons Attribution 4.0 International License, which permits use, sharing, adaptation, distribution and reproduction in any medium or format, as long as you give appropriate credit to the original author(s) and the source, provide a link to the Creative Commons licence, and indicate if changes were made. The images or other third party material in this article are included in the article's Creative Commons licence, unless indicated otherwise in a credit line to the material. If material is not included in the article's Creative Commons licence and your intended use is not permitted by statutory regulation or exceeds the permitted use, you will need to obtain permission directly from the copyright holder. To view a copy of this licence, visit http://creativecommons.org/licenses/by/4.0/.

\section{References}

1. de Buys Roessingh AS, Dinh-Xuan AT. Congenital diaphragmatic hernia: current status and review of the literature. Eur JPediatr. 2009;168(4):393-406.

2. Chandrasekharan PK, Rawat M, Madappa R, Rothstein DH, Lakshminrusimha S. Congenital diaphragmatic hernia-a review. Matern Health Neonatol Perinatol. 2017;3:6.

3. Greer JJ. Current concepts on the pathogenesis and etiology of congenital diaphragmatic hernia. Respir Physiol Neurobiol. 2013;189(2):232-40.

4. Brownlee EM, Howatson AG, Davis CF, Sabharwal AJ. The hidden mortality of congenital diaphragmatic hernia: a 20year review. J Pediatr Surg. 2009;44(2):317-20.

5. McHoney M. Congenital diaphragmatic hernia, managementin thenewborn. PediatrSurgInt. 2015;31(11):1005-13.

6. Colvin J, Bower C, Dickinson JE, Sokol J. Outcomes of congenital diaphragmatic hernia: a population-based study in Western Australia. Pediatrics. 2005;116(3):e356-e63.

7. Malowitz JR, Hornik CP, Laughon MM, Testoni D, Cotten CM, ClarkRH, etal. Management practice and mortality for infants with congenital diaphragmatic hernia. Am J Perinatol. 2015;32(9):887-94.

8. Kadir D, Lilja HE. Risk factors for postoperative mortality in congenital diaphragmatic hernia: a single-centre observational study. Pediatr Surg Int. 2017;33(3):317-23.

9. Duess JW, Zani-Ruttenstock EM, Garriboli M, Puri P, Pierro A, Hoellwarth ME. Outcome of right-sided diaphragmatic hernia repair: a multicentre study. Pediatr Surg Int. 2015;31(5):465-71.

10. PoberBR. Overviewofepidemiology, genetics, birth defects, and chromosome abnormalities associated with $\mathrm{CDH}$. Am J Med Genet C Semin Med Genet. 2007;145C(2):158-71.

11. Wickham H. ggplot2: elegant graphics for data analysis. New York: Springer; 2009.

12. $\mathrm{R}$ Core Team. The $\mathrm{R}$ project for statistical computing. $\mathrm{R}$ foundation. 2018. https://www.r-project.org/. Accessed 1 Dec2018.

13. Wynn J, Krishnan U, Aspelund G, Zhang Y, Duong J, Stolar $\mathrm{CJH}$, et al. Outcomes of congenital diaphragmatic hernia in the modern era of management. J Pediatr. 2013;163(1):114-119.e1. 
14. Bojanić K, Woodbury JM, Cavalcante AN, Grizelj R, Asay GF, Colby CE, et al. Congenital diaphragmatic hernia: outcomes of neonates treated at Mayo Clinic with and without extracorporeal membrane oxygenation. Paediatr Anaesth. 2017;27(3):314-21.

15. Petroze RT, Caminsky NG, Trebichavsky J, Bouchard S, LeNguyen A, Laberge J-M, et al. Prenatal prediction of survival in congenital diaphragmatic hernia: An audit of postnatal outcomes. JPediatr Surg. 2019; 54(5):925-931.

16. Burgos CM, Frenckner B, Luco M, Harting MT, Lally PA, Lally KP. Prenatally diagnosed congenital diaphragmatic hernia: optimal mode of delivery? J Perinatol. 2017;37(2):134-8.

17. Congenital Diaphragmatic Hernia Study Group, Lally KP, Lally PA, Lasky RE, Tibboel D, Jaksic T, et al. Defect size determines survival in infants with congenital diaphragmatic hernia. Pediatrics. 2007;120(3):e651-e7.

18. Seetharamaiah R, Younger JG, Bartlett RH, Hirschl RB, CongenitalDiaphragmatic HerniaStudy Group.. Factors associated with survival in infants with congenital diaphragmatic hernia requiring extracorporeal membrane oxygenation: a report from the Congenital Diaphragmatic Hernia Study Group. JPediatr Surg. 2009;44(7):1315-21.

19. Hung W-T, Huang S-C, Mazloum DE, Lin W-H, Yang H-H, Chou $\mathrm{H}-\mathrm{C}$, et al. Extracorporeal membrane oxygenation for neonatal congenital diaphragmatic hernia: the initial single-center experience in Taiwan. J Formos Med Assoc. 2017;116(5):333-9.

20. Öst E, Joelsson MÖ, Burgos CM, Frenckner B. Self-assessed physical health among children with congenital diaphragmatic hernia. Pediatr Surg Int. 2016;32(5):493-503.

21. Hoffman SB, Massaro AN, Gingalewski C, Short BL. Predictors of survival in congenital diaphragmatic hernia patients requiring extracorporeal membrane oxygenation: CNMC 15-year experience. J Perinatol. 2010;30(8):546-52.

22. Guner YSPTD. Cannulating the contraindicated: effect of low birth weight on mortality in neonates with congenital diaphragmatic hernia on extracorporeal membrane oxygenation. J Pediatr Surg. 2017. https://ac-els-cdncom.ez.srv.meduniwien.ac.at/S0022346817305341/1-s2.
0-S0022346817305341-main.pdf? tid=3d417d8a-b7d3-11 e7-9486-00000aab0f01\&acdnat=1508750535_2664ae0ff53b 18455afbdfba844dc4b1.

23. Bryner BS, Kim AC, Khouri JS, Drongowski RA, Bruch SW, Hirschl RB, et al. Right-sided congenital diaphragmatic hernia: high utilization of extracorporeal membrane oxygenation and high survival. JPediatrSurg. 2009;44(5):883-7.

24. Collin M, Trinder S, Minutillo C, Rao S, Dickinson J, Samnakay N.A modern era comparison of right versus left sided congenital diaphragmatic hernia outcomes. J Pediatr Surg. 2016;51(9):1409-13.

25. Fisher JC, Jefferson RA, Arkovitz MS, Stolar CJH. Redefining outcomes in right congenital diaphragmatic hernia. JPediatr Surg. 2008;43(2):373-9.

26. Montalva L, Lauriti G, Zani A. Congenital heart diseaseassociated with congenital diaphragmatic hernia: a systematic review on incidence, prenatal diagnosis, management, and outcome. J Pediatr Surg. 2019; 54(5):909-919.

27. Graziano JN, Congenital Diaphragmatic Hernia Study Group. Cardiac anomalies in patients with congenital diaphragmatichernia and their prognosis: a reportfrom the Congenital Diaphragmatic Hernia Study Group. J Pediatr Surg. 2005;40(6):1045-9. discussion 1049-1050.

28. Morini F, Goldman A, Pierro A. Extracorporeal membrane oxygenation in infants with congenital diaphragmatic hernia: a systematic review of the evidence. Eur J Pediatr Surg. 2006;16(6):385-91.

29. Vaja R, Bakr A, Sharkey A, Joshi V, Faulkner G, Westrope C, et al. The use of extracorporeal membrane oxygenation in neonates with severe congenital diaphragmatic hernia: a 26-year experience from a tertiary centre. Eur J Cardiothorac Surg. 2017;52(3):552-7.

30. Golden J, Jones N, Zagory J, Castle S, Bliss D. Outcomes of congenital diaphragmatic hernia repair on extracorporeal life support. Pediatr Surg Int. 2017;33(2):125-31.

Publisher's Note Springer Nature remains neutral with regard to jurisdictional claims in published maps and institutional affiliations. 